\title{
High performance of excitation system for synchronous generator based on modeling analysis
}

\author{
Yasir Abdulhafedh Ahmed, Yousif I. M. Al-Mashhadany, Mustafa Ahmed Nayyef \\ Electrical Engineering Department, Engineering College, University of Anbar, Iraq
}

\begin{tabular}{|c|c|}
\hline Article Info & ABSTRACT \\
\hline Article history: & $\begin{array}{l}\text { Mathematical description of electromechanical systems operation is powerful } \\
\text { parameter to get high performance with practical implement of the systems. }\end{array}$ \\
\hline Received Mar 18, 2020 & This paper describes a mathematical presentation for the behavior excitation \\
\hline Revised May 7, 2020 & system of synchronous generator based on the optimal values of the parameters. \\
\hline Accepted Jul 11, 2020 & $\begin{array}{l}\text { The study of the mathematical modeling for dynamics of excitation system } \\
\text { required the knowledge for the effect of each parameter to get the typical }\end{array}$ \\
\hline Keywords: & $\begin{array}{l}\text { values provided by the manufacturer implementing. The simulation of the final } \\
\text { model which obtained was conducted on Matlab version } 2019 \mathrm{~b} \text {. The final }\end{array}$ \\
\hline $\begin{array}{l}\text { Electromechanical system } \\
\text { Excitation modeling }\end{array}$ & $\begin{array}{l}\text { results of simulation for the mathematical model are satisfactory, and it } \\
\text { proves the ability of independence this model as practical implement. }\end{array}$ \\
\hline
\end{tabular}

This is an open access article under the $\underline{C C B Y-S A}$ license.

Synchronous generator

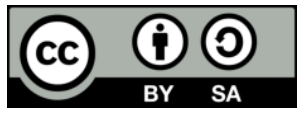

\section{Corresponding Author:}

Yousif I. M. Al-Mashhadany,

Department of Electrical Engineering,

College of Engineering, university of Anbar,

Anbar governorate, Ramadi, Iraq.

Email: yousif.mohammed@uoanbar.edu.iq

\section{INTRODUCTION}

Synchronous generators defined as machines that do work of transferring energy from their mechanical to electrical forms. It represents the main element and the basic base for generating electric energy in most power systems, so it will have the most impact on the work of the system as a whole. This explains the interest in studying it clearly in most studies related to the power system [1-3]. Excitation systems can be seen as most interesting components of synchronous generators. It includes equipment, machines, and devices, which works to provide DC current to the generator coils in addition to another basic mission, which is to control the machine and protect the power system, as its dynamic operation is a strong and rapid appearance on the reliability as well as stability of the generator.Therefore, the excitation system must be designed carefully. If the simulation design is required to simulate the performance of the synchronous machine in case the power system is stable [4-7].

In synchronous generators, the mechanical energy of a prime mover is converted to electrical energy with a constant frequency and specified voltage. The expression synchronous is defined as the compatibility that occurs inside the air gap between the speed of the rotating magnetic field and the speed of the rotating part, these two parameters are what produce the internal voltage. Most of the electric power in the world is produced by synchronous generators [8-11]. As a motor, it differs with induction in generating torque. It works in synchronization with the speed of rotation field, the excitation current generates this field within air gap, which is the field winds current at rated power $[12,13]$. This paper present the mathematical analysis, model, and simulation of an excitation system. 
The two main objects in this paper is to focusing on synchronous machine by one of its most important part called excitation system due to its importance in generation process, this is followed by preparing a simulation model for the machine, using a program concerned with modeling which is Matlab by its special part which is SimPowerSystems [2]. While the modeling process of synchronous generator excitation system, it must take into account the indeed performance of excitation equipment for both large and small disturbances if achieving of accurate simulation results are needed [3]. The base excitation system function is to control the current of the field of synchronous machine. The output voltage can be control by means of controlling of field winding current [4]. Because of the height of the field winding time constant, so it is required to forcing the field for quick control. When the operation of synchronous generators must be exactly simulated stability studies connected to power system, so there is a need to making such base systems like excitation modeled of more fairly [6]. The model must consider whole disturbances affects the performance of the synchronous generator. Any modeling type of any electrical machine like "synchronous generator" will begin by measurements made on actual model, that because it required for specifed of all main parameters related.

The other chance is obtaining the parameters of a generator from the majnufacturer itself, or by specified own parameters if the primary model belong to generator is under construction [8]. Hence, the model of generator can be achieved by employ of all mathemat formulas, which characterize the machine the scientific modeling method leads to reduce the research works which belongs to theory own values [10] and the results will be groups of generalizations related to several parts of actuality connected with specified rules. That is will all leads to lowering of complexity as a trying to make this actuality more comprehensible. The behavior of the original, which describes by Mathematical model, will be create as a result of all of the related investigation of the object of the research [11]. It should be provided with all base parameters belong to all behaviors which described by differential equations. It is conclude to say that the research associated with modeling include procedure of three steps: build of the model, the research in its attitude and its estimation [13]. The task relted simulation estimation can be accomplish by some steps which: determining the problem, mathematical model retrieve, create the program used in simulation, test the model of simulation, accomplishing simulation steps, estimation of results, return to the previous stage or "exit". On the other hand, all four models will be awarde with their own equations describing the mathematical model of the generator. The generator model can be forming from its own equivalent circuit [14]. That is an initiation point of formulation the base equations. The synchronous generators as indicate by its name, must drive on condition that there is a compatibility state between both the synchronous speed and frequency supplied [15]. Winding of stator always, three phase while the rotor winding usually carry DC current [16].

\section{EXCITATION SYSTEMS CLASSIFICATION}

The excitation system classified according to the power gain of excitation into three types $[17,18]$ :

\subsection{DC excitation systems}

The system provides the required field current applied to the rotating part coils of the synchronous machine directly by means of slip ring. The exciter may be driven either by the main shaft or detached driven motor of either separately-excited or self-excited.

\subsection{AC excitation system}

The AC excitation system defined as a rectification system placed in a direct way on the major shaft of the machine. Exciter provides field winding with DC current by rectifying the ac current by means of controlled or non-controlled rectifiers. AC excitation type could be further divided into two types, which are:

a. Rotor excitation system

Here the system constructed from (AC exciter, stationary and rotating parts). A full wave thyristor bridge rectifier will perform the rectification of ac output from the exciter and feed alternator field winding via slip ring.

b. Brushless excitation type

Known as a system constructed with (rectifier, alternator, exciter and a permanent magnet alternator). The exciter will no needed for brushes or slip rings. The main shaft drives it directly when DC is directly feeding to generator winding field. This system was developed to reduce the impact of very high field current in case of large generators. 


\subsection{Static excitation system(ST)}

This type characterized by the presence of a stationary state for all elements of the system, in these systems. The excitation current is obtained from the generator itself by means of slip rings, either by means of a three-phase step-down or by auxiliary windings. The main part of the transformer is connected to the generator conveyor. As for the secondary, it supplies the power to the rectifier in addition to supplies power to the controls and some equipment. In order for the generator to produce voltages, an excitation voltage is required, so an additional power source is required to existence current of the field for excite itself. An usual auxiliary power source is station batteries, used in the so-called field flashing. There are differences between the types of excitation systems, Table 1 illustrate the advantages and disadvantages of different excitation systems [18-22].

Table 1. Properties comparision of excitation systems [12]

\begin{tabular}{lllll}
\hline \multicolumn{1}{c}{ Parameter } & \multirow{2}{*}{ DC } & \multicolumn{2}{c}{ AC } & \multirow{2}{*}{ ST } \\
\cline { 3 - 4 } & & Stationary & Brushless & \\
\hline Excitation Transform supply & Low & Low & Low & Transform \\
machine Length & Moderate & Moderate & Lengthy & Shortened \\
Response time & low & Moderate. & Moderate & speedy \\
Parts needs maintenance & Slip ring and commutator & Slip ring & . & Slip ring \\
De-excitation & Moderate & Moderate & Low & Speedy \\
\hline
\end{tabular}

\section{MATHEMATIC MODEL FOR EXCITATION SYSTEMS}

Mathematic models (second, third, fifth, or seventh) order can be used for modeling of a synchronous generator. The most complex and accurate model that describe synchronous generators is called Seventh-order model [23]. This apply to analyse the dynamic behavior at case of normal conditions and case of fault conditions in a generator. The both DC and AC components in both stator and the rotor respectively were neglects when using the Fifth-order model. It is less complicated than the type of seventh order model so it is used, and it is applied a lot in the modeled of electrical power systems for the purpose of studying the transient stability in the steady state condition when writing the Kirchhoff Law of the electric grid [24, 25]. Deviations in frequency, the high-order harmonics, and behavior of the damped coils neglected in Third-order model. Its properties like simplicity and good dynamic decryption make it much used in synthesis and analysis process in control systems. Second-order type model is the more simple model for synchronous generator, it illustrate just the dynamics behavior of a rotation part [26].

\subsection{Mathematicall describe of excitation system}

An exciter's expressions is as follows:

$$
\begin{aligned}
& \tilde{v}_{e d}=-R_{e s} \tilde{l}_{e d}+w_{e}\left(L_{e i s}+L_{e m q}\right) \tilde{l}_{e q}-\left(L_{e i s}+L_{e m d}\right) \frac{d \tilde{l}_{e d}}{d t}+L_{e m q} \frac{d \tilde{l}_{e f d}}{d t} \\
& \tilde{v}_{e q}=-R_{e s} \tilde{l}_{e q}+w_{e}\left(L_{e l s}+L_{e m d}\right) \tilde{l}_{e d}+w_{e} L_{e m d} \tilde{l}_{e d}-\left(L_{e i s}+L_{e m q}\right) \frac{d \tilde{l}_{e q}}{d t} \\
& \tilde{v}_{e f d}=R_{e f d} \tilde{l}_{e f d}-L_{e m d} \frac{d \tilde{l}_{e d}}{d t}+\left(L_{e l f d}+L_{e m d}\right) \frac{d \tilde{l}_{e f d}}{d t}
\end{aligned}
$$

Combining generator (rectifier) linearized together to an exciter belong to DC load model, obtain:

$$
\begin{aligned}
& \tilde{v}_{e d c}=K_{138} \tilde{v}_{e d}+K_{239} \tilde{v}_{e q} \\
& \tilde{\imath}_{e d}=K_{4} \tilde{l}_{e d c}+K_{5} K_{8} \tilde{v}_{e d}+K_{5} K_{9} \tilde{v}_{e q} \\
& \tilde{\imath}_{e q}=K_{6} \tilde{l}_{e d c}+K_{7} K_{8} \tilde{v}_{e d}+K_{7} K_{9} \tilde{v}_{e q} \\
& K_{138}=K_{1}+K_{3} K_{8} \\
& \mathrm{~K}_{239}=\mathrm{K}_{2}+\mathrm{K}_{3} \mathrm{~K}_{9}
\end{aligned}
$$

Expression of the base generator's field winding, illustrates the DC of the exciter, as: 
$\tilde{v}_{a f d}=R_{a f d} \tilde{l}_{a f d}-L_{a m d} \frac{d \tilde{l}_{a d}}{d t}+\left(L_{a l f d}+L_{a m d}\right) \frac{d \tilde{l}_{a f d}}{d t}+L_{a m d} \frac{d \tilde{c}_{a k d}}{d t}$

Here, it can be written the voltage equation of the main generator:

$\tilde{v}_{a f d}=t_{a} \tilde{v}_{e d c}$

Similarly, for currents

$\tilde{\imath}_{a f d}=\frac{1}{t_{a}} \tilde{l}_{e d c}$

Substitution (9), (10), and (11) obtain the expression of exciter load:

$\tilde{v}_{e d c}=\frac{R_{a f d}}{t_{a}^{2}} \tilde{l}_{e d c}-\frac{L_{a m d}}{t_{a}} \frac{d \tilde{a}_{a d}}{d t}+\frac{\left(L_{a l f d}+L_{a m d}\right)}{t_{a}^{2}} \frac{d \tilde{l}_{a f d}}{d t}+\frac{L_{a m d}}{t_{a}} \frac{d \tilde{c}_{a k d}}{d t}$

The mathematic formula related to $\tilde{v}_{e d}$ and $\tilde{v}_{e q}$ possible to expressing by eliminating $\tilde{v}_{e d c}$ :

$$
\begin{aligned}
& \tilde{v}_{e d}=r_{e d d} \tilde{l}_{e d}+l_{e d d} \frac{d \tilde{l}_{e d}}{d t}+r_{e d q} \tilde{l}_{e q}+l_{e d q} \frac{d \tilde{e}_{e q}}{d t}-K_{9} l_{a e} \frac{d \tilde{e}_{e d}}{d t}+K_{9} l_{a e} \frac{d \tilde{e}_{e k d}}{d t} \\
& \tilde{v}_{e q}=r_{e q d} \tilde{l}_{e d}+l_{e q d} \frac{d \tilde{\tau}_{e d}}{d t}+r_{e q q} \tilde{l}_{e q}+l_{e q q} \frac{d \tilde{l}_{e q}}{d t}-K_{8} l_{a e} \frac{d \tilde{l}_{a d}}{d t}+K_{8} l_{a e} \frac{d \tilde{l}_{a k d}}{d t}
\end{aligned}
$$

where:

$$
\begin{aligned}
& K_{\text {det }}=K_{4} K_{7}\left(K_{9} K_{138}-K_{8} K_{239}\right)+K_{5} K_{6}\left(K_{8} K_{239}-K_{9} K_{138}\right) \\
& r_{e d d}=\frac{K_{6} K_{239}+K_{7} K_{9} \frac{R_{a f d}}{t_{a}^{2}}}{K_{\text {det }}} \\
& l_{\text {edd }}=\frac{K_{7} K_{9}\left(L_{\text {alf }}+L_{\text {amd }}\right)}{t_{a}^{2} K_{\text {det }}} \\
& l_{\text {edq }}=\frac{K_{5} K_{9}\left(L_{\text {alfd }}+L_{\text {amd }}\right)}{t_{a}^{2} K_{\text {det }}} \\
& r_{e d q}=\frac{K_{6} K_{138}+K_{7} K_{8} \frac{R_{a f d}}{t_{a}^{2}}}{K_{\text {det }}} \\
& r_{e d q}=\frac{K_{4} K_{138}+K_{5} K_{8} \frac{R_{a f d}}{t_{a}^{2}}}{K_{d e t}} \\
& l_{\text {eqd }}=\frac{K_{7} K_{8}\left(L_{\text {alfd }}+L_{\text {amd }}\right)}{t_{a}^{2} K_{\text {det }}} \\
& l_{\text {eqq }}=\frac{K_{5} K_{8}\left(L_{\text {alfd }}+L_{\text {amd }}\right)}{t_{a}^{2} K_{\text {det }}} \\
& l_{a e}=\frac{K_{4} K_{7}-K_{5} K_{6}}{t_{a} K_{d e t}} L_{a m d} \\
& \tilde{l}_{a f d}=h_{a e d} \tilde{l}_{e d}+h_{a e d} \tilde{l}_{e q}
\end{aligned}
$$

where:

$$
h_{\text {aed }}=\frac{K_{138} K_{7} K_{9}-K_{239} K_{7} K_{8}}{t_{a} K_{\text {det }}}
$$




$$
h_{a e q}=\frac{K_{239} K_{5} K_{8}-K_{138} K_{5} K_{9}}{t_{a} K_{\text {det }}}
$$

It can be obtain linear state-space can be represented by substitute formulas (14) and (15) by (1) and (2), and the resultant illustration form of a model possible to obtain by decrease order of the system by only one order.

\subsection{The generator mathematil model}

In this work, it's using the mathematic model for the generator for the purpose of simulate the model of exciter which possible to obtain by made substitution the current of base generator's field mentioned in (24), giving $(13,14)$ :

$$
\begin{gathered}
\begin{aligned}
v_{e d}=-R_{a s} i_{e d}+ & w_{a}\left(L_{a l s}+L_{a m q}\right) i_{e q}-w_{a} L_{a m q} i_{a k q}-\left(L_{a l s}+L_{a m d}\right) \frac{d i_{a d}}{d t} \\
& +L_{a m d} \frac{d\left(h_{a e d} i_{e d}+h_{a e q} i_{e q}\right)}{d t}+L_{a m d} \frac{d i_{a k d}}{d t} \\
v_{e q}=-R_{a s} i_{e q}- & w_{a}\left(L_{a l s}+L_{a m d}\right) i_{a d}+w_{a} L_{a m d}\left(h_{a e d} i_{e d}+h_{a e q} i_{e q}\right) \\
& +w_{a} L_{a m d} i_{a k q}-\left(L_{a l s}+L_{a m d}\right) \frac{d i_{a d}}{d t}+L_{a m d} \frac{d i_{a k d}}{d t}
\end{aligned} \\
\begin{aligned}
0=R_{a k d} i_{a k d}- & L_{a m d} \frac{d i_{a d}}{d t}+L_{a m d} \frac{d\left(h_{a e d} i_{e d}+h_{a e q} i_{e q}\right)}{d t}+\left(L_{a l k d}\right. \\
& \left.+L_{a m d}\right) \frac{d i_{a k d}}{d t} \\
0=R_{a k q} i_{a k q}- & L_{a m q} \frac{d i_{a q}}{d t}+\left(L_{a l k q}+L_{a m q}\right) \frac{d i_{a k q}}{d t}
\end{aligned}
\end{gathered}
$$

The mathematic description of load of generator's will demonstrate by applying $\tilde{\mathfrak{l}}_{\text {load }}$ expression:

$\tilde{\imath}_{a d c}=C \frac{d \tilde{v}_{a d c}}{d t} \tilde{l}_{l o a d}$

New formulation of $\tilde{v}_{a d}$ and $\tilde{v}_{a q}$ by derive $\tilde{l}_{a d c}$ as:

$$
\begin{aligned}
& \tilde{v}_{a d}=r_{a d d} \tilde{l}_{e d}+r_{a d q} \tilde{l}_{a q}+h_{a d d c} \tilde{v}_{a d c}+c_{a d d c} \frac{d \tilde{v}_{a d c}}{d t}+r_{a d l} \tilde{l}_{l o a d} \\
& \tilde{v}_{a q}=r_{a q d} \tilde{l}_{e d}+r_{a q q} \tilde{l}_{a q}+h_{a q d c} \tilde{v}_{a d c}+c_{a q d c} \frac{d \tilde{v}_{a d c}}{d t}+r_{a q l} \tilde{l}_{l o a d}
\end{aligned}
$$

where:

$$
\begin{aligned}
& c_{\text {det }}=\frac{1}{c_{5} c_{10}-c_{6} c_{9}} \\
& r_{a d d}=c_{d e t} c_{10} \\
& r_{a d q}=-c_{d e t} c_{6} \\
& h_{a d d c}=-c_{\operatorname{det}}\left(c_{6} c_{8}-c_{4} c_{10}\right) \\
& c_{a d d c}=-c_{\operatorname{det}}\left(c_{6} c_{7}-c_{3} c_{10}\right) C \\
& r_{a d l}=c_{\operatorname{det}}\left(c_{6} c_{7}-c_{3} c_{10}\right) \\
& r_{a d q}=-c_{\mathrm{det}} c_{9}
\end{aligned}
$$




$$
\begin{aligned}
& r_{a q q}=c_{\mathrm{det}} c_{5} \\
& h_{a q d c}=c_{\mathrm{det}}\left(c_{4} c_{9}-c_{5} c_{8}\right) \\
& c_{a q d c}=c_{\mathrm{det}}\left(c_{3} c_{9}-c_{5} c_{7}\right) C \\
& r_{a q l}=c_{\mathrm{det}}\left(c_{3} c_{9}-c_{5} c_{7}\right)
\end{aligned}
$$

In expressions (32-33), ĩload should be considered as an input of system, which will be applied for substitution by armature voltages, such in formulas (27), (28) respectively.

\section{SIMULATION AND ANALYSIS OF THE EXCITATION SYSTEM}

Matlab/Simulink Ver. 2019b used to perform the simulation. An excitation system here is a mini synchronous machine linked with the main alternator shaft oneself. As for the current rectifier, it is a bridge rotating and placed at the shaft of synchronous machine, cancelling dependence on slip rings in order to obtain a DC current to the field coils. The generator specifications (1500 rpm, $50 \mathrm{~Hz}, 2 \mathrm{MVA}, 400 \mathrm{~V})$ synchronous generator joint with a diesel motor as a prime mover (see Figure. 1). It can be considered that the voltage, which supplied to the rotor is a convenience voltage to covered the $100 \mathrm{~A}$ as a nominal field winding current (Ifn) which led to nominal field winding voltage which a value is $9.2837 \mathrm{~V}$. Exciting thing is a synchronous machine (Premensioned model as No. 1) of $8.1 \mathrm{kVA}, 400 \mathrm{~V}, 50 \mathrm{~Hz}, 1500 \mathrm{RPM}$. By means of $400 \mathrm{~V} / 12 \mathrm{~V}$ step-down transformer, an output voltage $(400 \mathrm{~V})$ refer to exciter which supplied to the rectifier was adapted.

As a result of large field inductance, filtering was not needed. Field connections subsystems are used to measure terminal voltages the field referred to synchronous machine model. A current source voltage which should go to the $V_{f}$ of the generator is a block type input as shown in Figure 1. Figure 2, shows all details of electrical part of the excitation system. The parameters which the exciter system deals with all synchronous generator are explain by Figure 2, make the voltage of synchronous generator uniform, be accomplish by means of controlling the exciting Vf. (PI type) controller that has to do a comparison the measured potential i.e (positive sequence voltage) with $1 \mathrm{pu}$ as a base was performed. To make the simulation speed more fast it can be using discretized (TS $=50 \mathrm{US}$ ). Figure 3 illustrates all simulation results, (a) The volage and current response exciter system (b) The final speed response based high performance design.

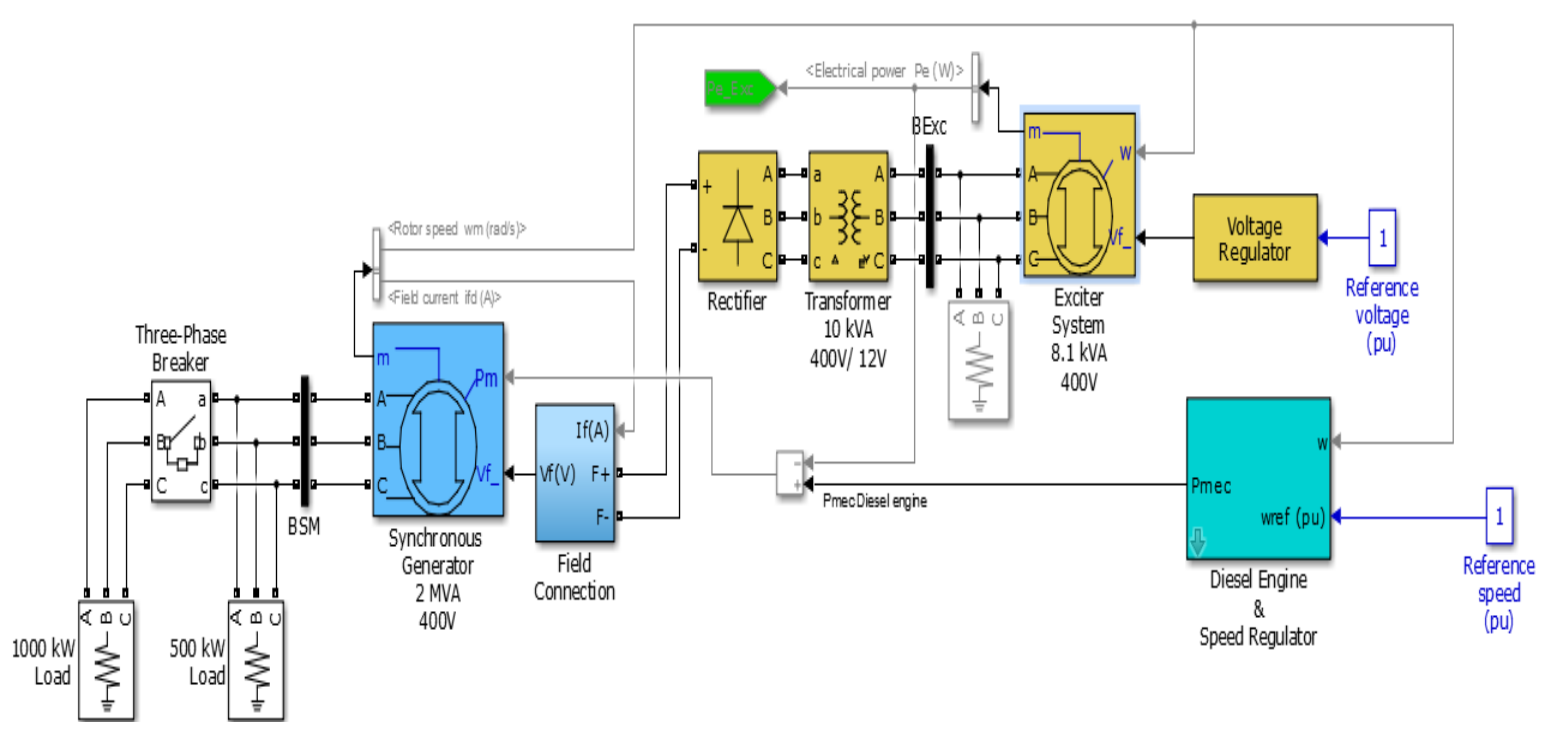

Figure 1. Synchronous generator and exciter system simulation 

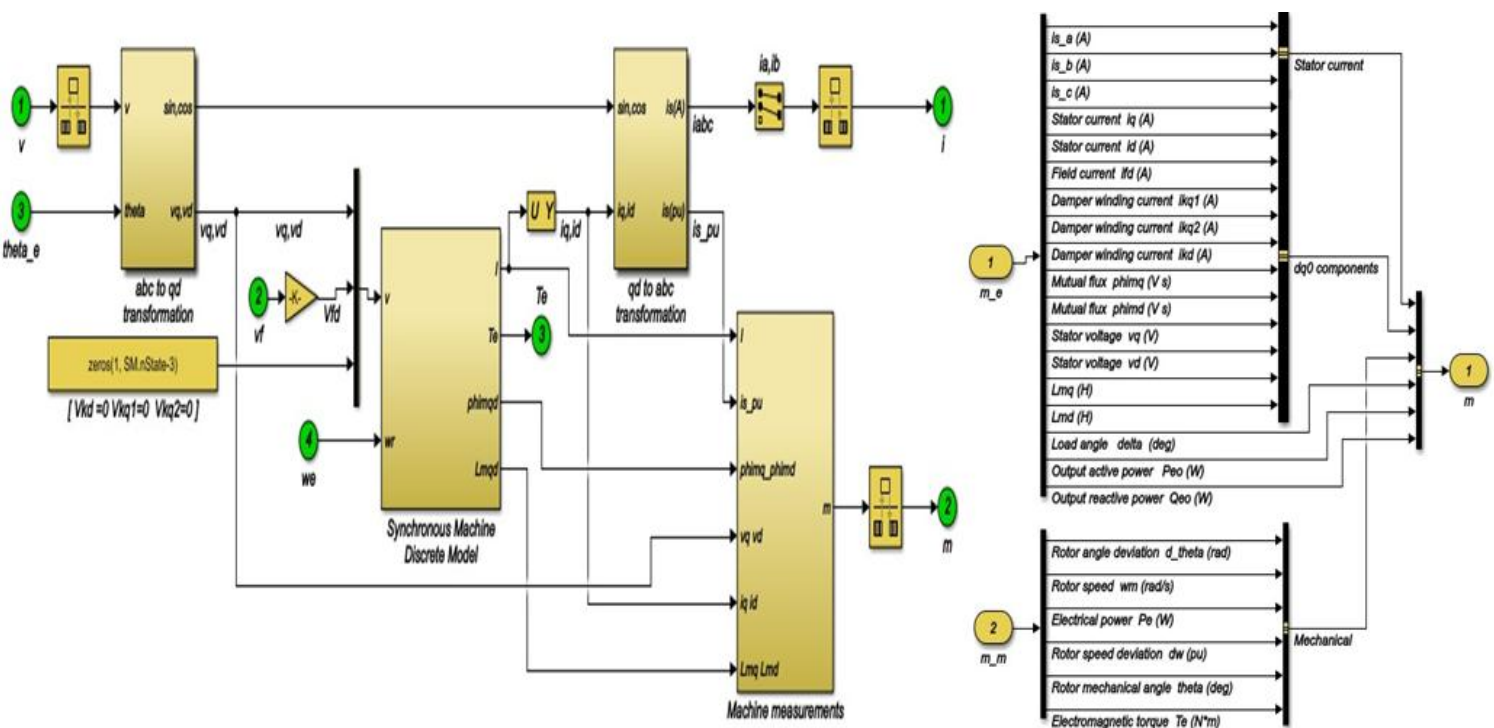

Figure 2. Detail of electrical part of the excitation system

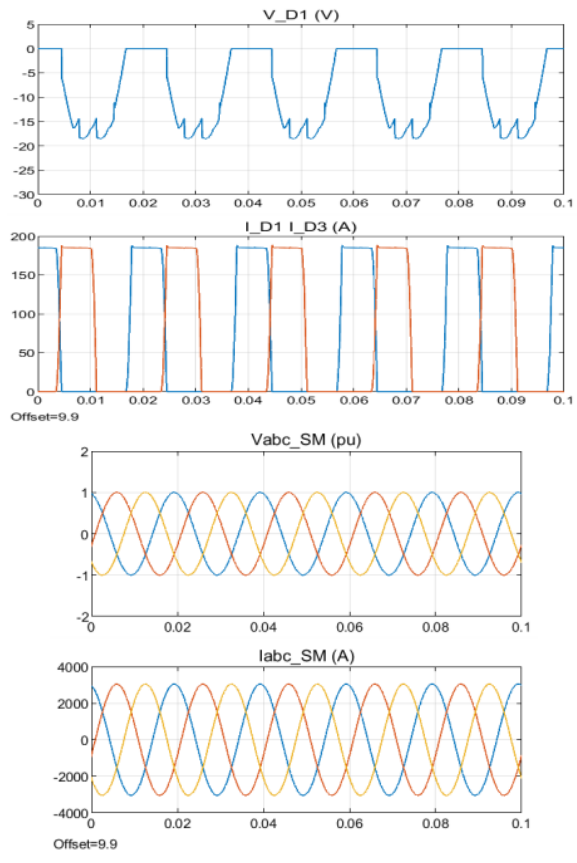

(a)
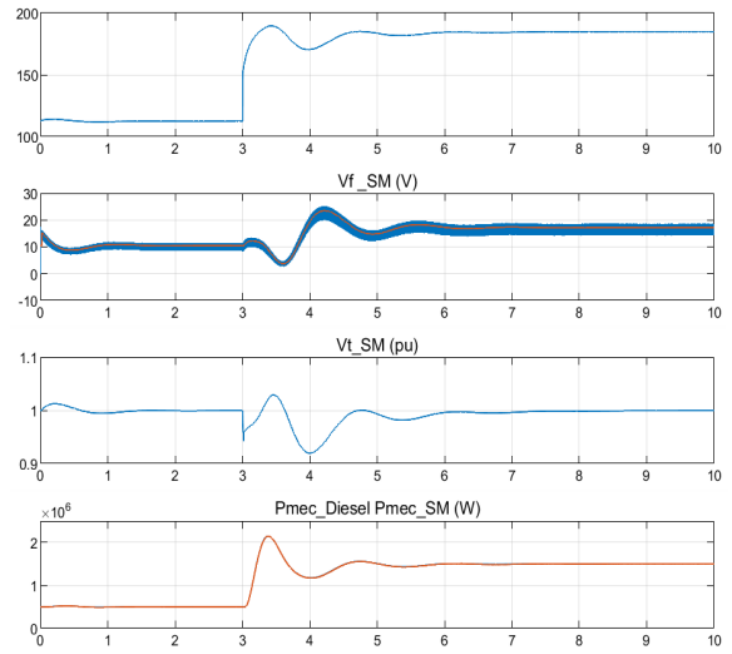

Speed (pu)

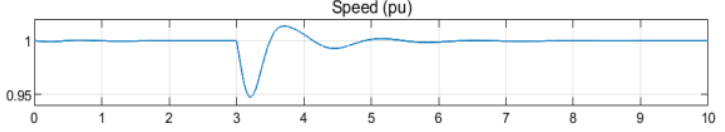

(b)

Figure 3. Simulation results based in high performance, (a) The volage and current response exciter system

(b) The final speed response based high performance design

\section{CONCLUSION}

The mathematical model obtained by adopting the principle of obtaining the best performance for each component of the system can call simulation of the synchronous generator by analyzing all electrical units And the mechanic is just. Through this simulation to monitor the dynamic behavior of a synchronous generator with the excitation system in all working conditions and in all alfunctions. And characterized by the possibility of changing all elements that affect the behavior of the system in all its initial and final cases. When examining the results obtained, we find that the simulation of the transit part by operating the system was less than a second, and this confirms that all elements operate with high performance values. Therefore, it can be said that the components of the design of this system are calculated in a very simple, accurate and correct manner, therefore it can be used in quality control checks and areas of training and teaching in laboratories that support ability systems.

High performance of excitation system for synchronous generator based on... (Yasir Abdulhafedh Ahmed) 


\section{REFERENCES}

[1] M. Miskovic, M. Mirosevic and M. Milkovic, "Analysis of Synchronous Generator Angular Stability Depending on the Choice of the Exitacion System," Journal of Energy : Energija, vol. 58 no. 4, pp. 430-445 2009.

[2] R. Majumder, B. Berggren and M. Larsson, "Development and comparison of DC grid model in powerfactory and Dymola for controller design," 2013 IEEE Power \& Energy Society General Meeting, Vancouver, BC, pp. 1-5, 2013.

[3] R. Ramya and K. Selvi, "Simulation of Synchronous Generator with Fuzzy based Automatic Voltage Regulator," International Journal of Electrical and Computer Engineering, vol. 2, no. 6, pp. 798-805, 2012.

[4] Y. I. Al-Mashhadany, "Modeling and simulation of Adaptive Neuro-Fuzzy controller for Chopper-Fed DC Motor Drive," 2011 IEEE Applied Power Electronics Colloquium (IAPEC), Johor Bahru, pp. 110-115, 2011.

[5] M. O. Oliveira, et.al., "Design and Analysis of Brushless Self-Excited Three-Phase Synchronous Generator," International Conference on Renewable Energies and Power Quality (ICREPQ'12), Santiago de Compostela, 2012, pp. 1659-1664

[6] W. Leonhard, "Control of Electrical Drivers," Berlin, Heidelberg, NewYork, Springer, pp. 51-63, 2001.

[7] Y. I. Al Mashhadany, F. Amir and N. Anwer, "Modeling, Simulation and Analysis of Excitation System for Synchronous Generator," Asian Journal of Engineering and Technology, vol. 2, no. 5, pp. 430-437, 2014

[8] B. K Bose, "Modern Power Electronics and AC Drivers," New Jersey, USA, Prentice Hall, 2012.

[9] D. Jolevski, "Exitacion System of Synchronous Generator", Faculty of Electrical Engineering, Mechanical Engineering and Naval Architecture,Split, 2009.

[10] T. Øyvang, G. J. Hegglid and B. Lie, "Models of Synchronous Generators With Excitation System, for Transient Power System Studies," IFAC-PapersOnLine, vol. 51, no. 2, pp. 91-96, 2018.

[11] Qiao Chen, Li Wan, Kunpeng Zhou, Kai Ding, Jun He and Yuchuan Hu, "Modeling and Simulation of Large Synchronous Generator Excitation System with PSASP" 4th International Conference on Mechatronics, Materials, Chemistry and Computer Engineering (ICMMCCE 2015), Xi' an, pp. 2700-2708, 2015.

[12] H. A. Kadhim, N. S. Ali and D. M. Abdulsahib, "Management and archiving system for metal detection robot using wireless-based technology and online database registry," International Journal of Power Electronics and Drive System, vol. 10, no. 1, pp. 219-229, 2019.

[13] E. Ludwig, M. L. Crow, L. Erickson and K. Shah, "A feasibility study of on-line excitation system parameter estimation," in IEEE Transactions on Power Systems, vol. 13, no. 3, pp. 910-916, 1998.

[14] R. Rudra, S. Bhuvad, D. Humbare, S. More and P. Tisulkar, "A review On- Automatic Excitation of Synchronous Motor using Single Phase Full Wave Controlled Rectifier," International Research Journal of Engineering and Technology, vol. 6, no. 9, pp. 804-808, 2019.

[15] Wei Liu and Changqing Zhu, "Modeling and Simulation of Excitation System for Third Harmonic Brushless Synchronous Generator" IOP Conf. Series: Materials Science and Engineering, vol. 563, no. 3, pp. 1-8, 2019.

[16] A. Hamed and A. Hazzab, "Modeling and Real-Time Simulation of Induction Motor Using RT-LAB," International Journal of Power Electronics and Drive System, vol. 9, no. 4, pp. 1476-1485, 2018.

[17] W. E. Vanço, F. B. Silva, F. A. S. Gonçalves, E. O. Silva, C. A. Bissochi and L. M. Neto, "Experimental analysis of a self-excited induction generators operating in parallel with synchronous generators applied to isolated load generation," in IEEE Latin America Transactions, vol. 14, no. 4, pp. 1730-1736, 2016.

[18] S. Tsegaye and K. A. Fante, "Analysis of Synchronous Machine Excitation Systems: Comparative Study," World Academy of Science, Engineering and Technology International Journal of Energy and Power Engineering, vol. 10, no.12, pp. 1492-1496, 2016.

[19] N. Jiao, W. Liu, Z. Zhang, T. Meng, J. Peng and Y. Jiang, "Field Current Estimation for Wound-Rotor Synchronous Starter-Generator With Asynchronous Brushless Exciters," in IEEE Transactions on Energy Conversion, vol. 32, no. 4, pp. 1554-1561, 2017.

[20] F. A. Hasan and L. J. Rashad, "Fractional-order PID controller for permanent magnet DC motor based on PSO algorithm," International Journal of Power Electronics and Drive System, vol. 10, no. 4, pp. 1724-1733, 2019.

[21] J. Liu, Y. Miura and T. Ise, "Comparison of Dynamic Characteristics Between Virtual Synchronous Generator and Droop Control in Inverter-Based Distributed Generators," in IEEE Transactions on Power Electronics, vol. 31, no. 5, pp. 3600-3611, 2016.

[22] M. Brezovec, I. Kuzle and M. Krpan, "Detailed Mathematical and Simulation Model of a Synchronous Generator Journal of Energy, vol. 64, no. 1-4, pp. 102-129, 2015.

[23] V. Jerkovic, K. Miklosevic and Z. Spoljaric, "Excitation System Models of Synchronous Generator" Conference: 28 th International Conference Science in Practice, September 2018.

[24] B. Zaker, G. B. Gharehpetian, M. Karrari and N. Moaddabi, "Simultaneous Parameter Identification of Synchronous Generator and Excitation System Using Online Measurements," in IEEE Transactions on Smart Grid, vol. 7, no. 3, pp. 1230-1238, 2016.

[25] W. S. Pambudi, E. Alfianto, A. Rachman, D. P. Hapsari, "Simulation design of trajectory planning robot manipulator," Bulletin of Electrical Engineering and Informatics ,vol. 8, no. 1, pp. 196-205, 2019.

[26] A. Kutsyk, M. Semeniuk and O. Kuznyetsov, "An application of fuzzy voltage regulator to a static excitation system of a phase compound synchronous generator," 2017 IEEE International Young Scientists Forum on Applied Physics and Engineering (YSF), Lviv, pp. 46-49, 2017. 


\section{BIOGRAPHIES OF AUTHORS}
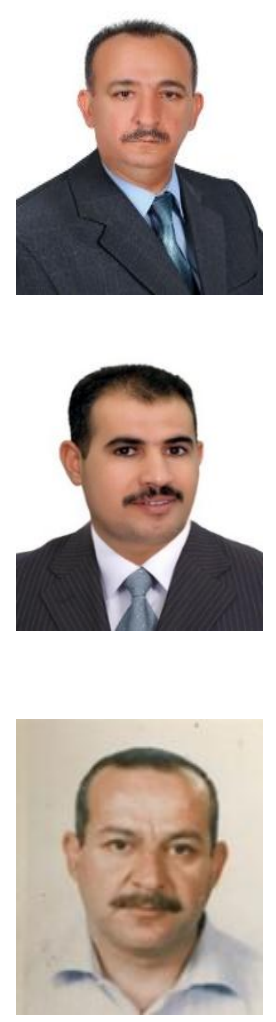

Yasir Abdulhafedh Ahmed was born in Alanbar, Iraq in 1964. He received his B.Sc degree from Basrah University, Engineerng College in 1988. He received his M.Sc degree from University of Technology in 2005. He is teacher in Department of Electrical engineering, College of Engineering, Al-Anbar University, and Ramadi-Iraq. His area of interest includes power system analysis, power system protection, and distribution networks in power system.

Yousif Ismail Mohammed Al-Mashhadany is a lecturer in Electrical Engineering Department - College of Engineering (Control Engineering). Senior member IEEE, He received the B.Sc. (1995), M.Sc. (1999), and Ph.D (2010) in Department of Electrical and Electronic Engineering from the Rashid School of Engineering and Science/University of Technology in Baghdad/Iraq. He complete postdoctoral fellow research in Electrical Engineering-control Department, University of Malaya in Malaysia (UMPEDAC) in 2012. He works since 2004, a lecturer in the Department of Electrical Engineering/Engineering College/University of Anbar. He has many publishing that included three books, two chapters, thirty seven Journals paper most of them (Clarivate, Scopus and international journal), and thirty two conferences paper.

Mustafa ahmed nayyef was born in Alanbar, Iraq in 1963. He received his B.Sc. degree from sarajevo University, Engineering College in 1985. He received his M.Sc. degree from University of Belgrade in 1987. He is teacher in Department of Electrical engineering, College of Engineering, Al-Anbar University. 